\title{
Preschoolers use prosodic mitigation strategies to encode polite stance
}

\author{
Iris Hübscher ${ }^{1}$, Martina Garufi ${ }^{2,1}$, Pilar Prieto ${ }^{3,1}$ \\ ${ }^{1}$ Departament de Traducció i Ciències del Llenguatge, Universitat Pompeu Fabra, Barcelona, Spain \\ ${ }^{2}$ Scuola di Lettere e Beni culturali, Università di Bologna, Italy \\ ${ }^{3}$ Institució Catalana de Recerca i Estudis Avançats, ICREA, Barcelona, Spain
}

iris.huebscher@upf.edu, martinagarufi91@gmail.com, pilar.prieto@upf.edu

\begin{abstract}
While prosody has been shown to act as a syntactic bootstrapper in early language acquisition, little is known about the role that prosody plays in the later development of a child's ability to communicate pragmatic information such as the expression of politeness. The goal of this paper is to investigate whether preschool children use prosody earlier and more prominently than lexical and morphosyntactic cues to signal a polite stance. To this end, 64 three- to five-year-old Catalan-dominant children participated in a cross-sectional study involving a request production task under four different conditions, with interlocutors either a classmate or an unfamiliar adult (low/high social distance), and the 'cost' to the interlocutor's face either low or high. The results showed that preschool children tend to use mitigating prosodic strategies to encode a polite stance early on and more markedly than they use lexical or morphosyntactic markers. These findings are consistent with what other research has found regarding the prosodic mitigation strategies used by Catalan-speaking adults to mark polite stance.
\end{abstract}

Index Terms: acquisition of politeness, prosodic development, polite stance

\section{Introduction}

'Politeness' involves attempting to mitigate face threats implied by any action that implies a degree of imposition on an interlocutor, such as making a request [1]. Politeness theory predicts a certain interaction between the dimensions of the social context and the use of face redress strategies, whereby requesting something from a person who has higher power or greater social distance will require more face-saving strategies, and the same will be true of requests intended to show a higher degree of imposition or cost to the 'face' of the person who receives the request.

The importance of prosody as one of those mitigating strategies has long been recognized [1], however, only more recently has research been taking a more global perspective on the relationship between prosody and politeness. Recent research on the interface between prosody and politeness has analysed different kinds of prosodic cues like pitch as well as intensity, syllable duration and voice quality (jitter, shimmer and $\mathrm{H} 2-\mathrm{H} 1$ as an index of breathiness). In Catalan, for example, a reduction in pitch height, longer syllable duration, less intensity, a decrease in jitter and shimmer, and an increase in
$\mathrm{H} 2-\mathrm{H} 1$ have all been found to be linked to politeness marking $[2,4]$. Similar findings have been made for Korean [3].

The question we will pursue here has to do with how children go about learning to recognise and use such prosodic politeness strategies. To date, most research on children's production and perception of politeness has focused on lexical and morphosyntactic cues ([5], [6], [7], [8], [9], [10], [11], [12], [13]). With regard to lexical cues, it has been found that children are usually socialised early into politeness routines through forms such as thank you, please, and I'm sorry ([5], [11], [12]). As for morphosyntactic strategies, children mainly use direct requests in early childhood, and the ability to tailor their language in order to take into account a listener's age and status and the cost of the exchange only begins to appear around ages four or five ([6], [7], [8], [9], [10]). There are only a few studies that have examined children's perception and production of pitch in connection with politeness ([14], [15]). These studies found that children struggled till age five to distinguish an interrogative from an imperative intonation (though see [16] for evidence that this ability occurs earlier. Nonetheless, on balance little is known about how different prosodic cues such as intensity, pitch height, duration and voice quality develop over the preschool years and the role they play in children's acquisition of pragmatic meanings such as politeness.

Generally, research on children's language acquisition has highlighted the role of prosody as a syntactic bootstrapper, that is, certain types of prosodic features have been shown to guide children's initial sensitivity to word order and syntactic structure (see [17]; also [18]). Recently it has been suggested that prosody might play a similar role in the acquisition of more complex pragmatic meanings (see [19]). Yet, thus far there has been no research on whether prosody might work as a scaffolding device for children as they develop the ability to understand and convey an interpersonal politeness stance. In the current study we would like to fill this gap by exploring how three- to five-year-olds go about indexing polite stance in request situations. In particular, we will examine (1) if and how Catalan-speaking children mitigate their requests depending on the social parameters of social distance and cost (2) whether these children use prosodic strategies earlier and more prominently than lexical and morphosyntactic strategies; and (3) whether the older children in this sample show enhanced abilities in this regard relative to the younger children. 


\section{Methods}

\subsection{Participants}

Sixty-four Catalan-dominant speaking children were recruited at four public preschools in the Barcelona area. They were divided into two groups by age, with Group 1 consisting of younger children (mean age $3 ; 8, S D$.464) and Group 2 consisting of older children (mean age 5;1, SD 0.495). Both groups were balanced for gender, each containing 17 girls and 17 boys. Children were recruited at four Catalan public preschools around the Barcelona area. Parental consent was obtained before the experiment, and parents also completed language exposure questionnaires [20] in order to ensure that the participating children were predominantly exposed to Catalan (as opposed to Spanish) on a daily basis (mean percentage of overall exposure to Catalan: $85 \%, S D=0.158$ ).

\subsection{Materials}

The experiment was reminiscent of a Discourse Completion Task (DCT) [21] but placed the children in real situations rather than hypothetical ones, thereby removing the metacognitive layer required for a DCT (we used an adaptation of the procedure followed in [22]). The four pre-planned target situations in the experiment varied along two politeness axes, namely (a) social distance between interlocutors (low vs. high), and (b) the cost to the interlocutor's face of the request (high vs. low), as illustrated in Figure 1 below.

FIGURE 1: Descriptions of the four contexts in which requests were elicited and pictures of the objects requested used in each situation

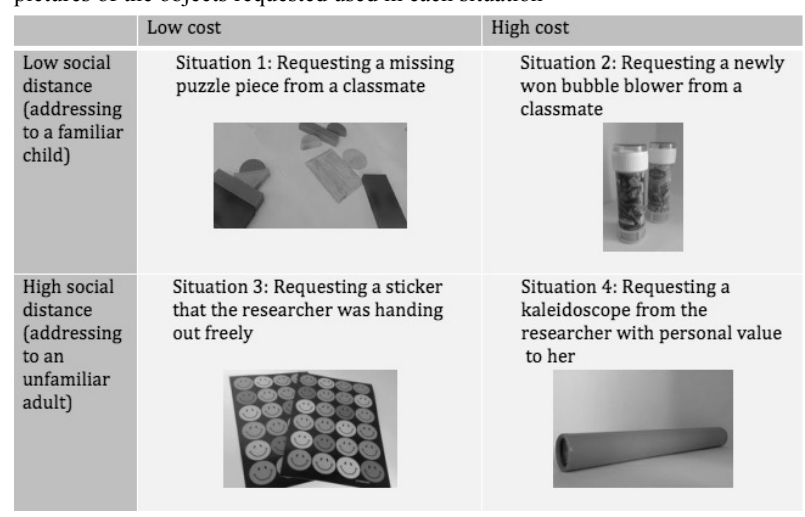

\subsection{Procedure}

The children were tested in pairs in a quiet room at their respective preschools. The two children were seated at adjacent sides of a table. Researcher 1, a native speaker of Catalan, sat beside them, giving instructions and guiding the children through the experiment. Researcher 2 sat at the corner opposite the children and managed the two video cameras, each focused on one child, which recorded all interactions. Also, as an unfamiliar adult seated farthest from the children, Researcher 2 served as the interlocutor in the high social distance context.

The experimental session lasted about ten minutes. Scrutiny of the video material collected showed a total of 231 verbal requests being made by the participating children. This was somewhat short of the 256 requests that could potentially have been produced ( 64 children $\times 4$ situations) but there were 25 instances in which a child failed to produce a request either because they were too shy or because they did not really want the object in question. In addition to these 231 verbalised requests, the video recordings showed 11 occasions where a request was made by non-verbal means only. Such non-verbal requests were not included in the present analysis.

\subsection{Data coding}

The total number of requests which contained speech $(\mathrm{N}=231)$ were coded. PRAAT [23] (Boersma \& Weenink, 2017) was used for the prosodic coding and notes were entered manually in an Excel spreadsheet for the lexical and morphosyntactic coding. From the literature on the expression of politeness in Catalan (see [4], [24] and [25]), we know that there are a number of ways requests can be modified in order to make them less face-threatening and that adults do so depending on the imposition of the request (cost) and the social distance between speakers.

Prosodic coding: The prosodic coding was carried out based on [4]'s study on the prosodic correlates of mitigation in Catalan formal register. First, a set of manual annotations were added to the PRAAT output, as follows:

Tier 1: Orthographic transcription of the recorded requests, separated by words.

Tier 2: Syllables, manually segmented. They were marked as (s) and were used to analyse duration patterns.

Tier 3: Final intonation, roughly classified into falling and rising pitch contour.

Tier 4: Intonation patterns, labelled in accordance with the Cat_ToBI framework [26]. The two graphs in Figure 2 illustrate these four tiers, using as examples the two most frequent intonation patterns found in the data, a direct directive (statement) with falling pitch and an indirect directive (question request) with rising pitch.

FIGURE 2: PRAAT output for the requests Vull això 'I want this' (falling pitch contour, left panel) and Me'l deixes? 'Can you give it to me?' (rising pitch contour, right panel). Each shows, from top to bottom, waveform, spectrogram, F0 contour, orthographic transcription, final intonation and intonation pattern.

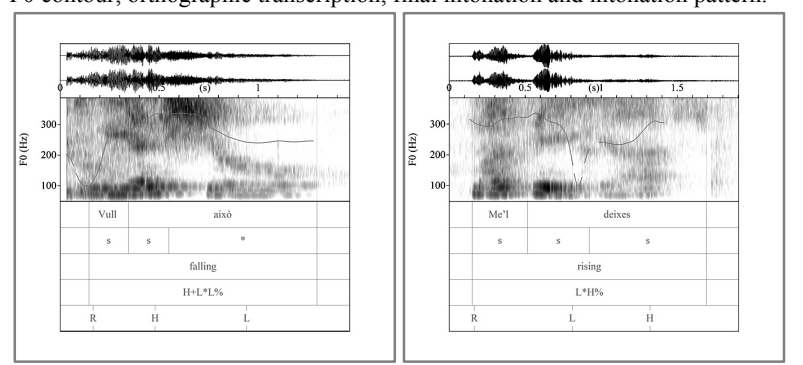

Another set of prosodic markers, namely pitch, intensity and voice quality, were automatically extracted using PRAAT for each syllable in our recordings. Voice quality measures recorded were average pitch (in $\mathrm{Hz}$ ), intensity (in $\mathrm{dBs}$ ), perturbation by amplitude (shimmer), perturbation by F0 period (jitter) and the harmonic differential (the difference in amplitude between the first and second harmonics, F1-F0, in $\mathrm{Hz})$.

Lexical and morphological coding: According to the literature on Catalan [4, 22, 23], politeness is conveyed in requests by means of (1) indirect speech act types (direct 
directive: Vull això 'I want this' vs. indirect directive: Em dones això? 'Can you give that to me?'), (2) downgraders like potser 'maybe', which adds hesitation, (3) formal address forms (informal $t u$ vs. formal vostè), (4) the conditional mood (indicative: pots 'can you' vs. conditional: podries 'could you') and (5) lexical politeness cues such as si us plau 'please'. The combination of these five cues determines the extent to which a request is perceived as more or less polite. However, in our dataset only two of these cue types occurred, namely indirect directives and the lexical marker si us plau 'please'. Notes on the presence of these two cues were taken on an Excel spreadsheet for each request in the dataset.

\subsection{Reliability of the coding}

Because the coding was carried out by two researchers (the first and second authors), steps were taken to standardise it and strengthen inter-rater reliability. The two researchers first worked together to analyse a subset of recordings mutually agree on coding schemes for prosodic and lexical/morphosyntactic markers. These schemes were then applied to the full dataset by one of the researchers. Finally, this coding was reviewed by the other researcher. Any differences of opinion regarding instances of coding were discussed until agreement was reached.

\subsection{Statistical analysis}

All statistical analyses were carried out using IBM SPSS Statistics v24 software. More specifically, a series of Generalized Linear Mixed Models (GLMMs) were undertaken to compare the values found for the two levels of each of three fixed factors: SOCIAL DISTANCE (two levels: low vs. high), COST to interlocutor's face (two levels: low vs. high) and AGE (two levels: younger vs. older). Random intercept was specified for Subject. The dependent variables were (1) lexical/morphosyntactic cues: presence of indirect directives and/or please; and (2) prosodic cues: intonation contour (rising vs. falling), as well as mean syllable duration, mean pitch (calculated from the mean of all syllables), mean jitter, shimmer, F1-F0 and intensity. The lexical and morphological cues were count in nature (i.e., a feature may be present one or more times in a particular request), as were some of the prosodic cues such as intonation pattern. On the other hand, the prosodic phonetic correlates such as duration, pitch, intensity and voice quality were all gradient in nature.

\section{Results}

In section 3.1 we analyse the 231 verbal requests in relation to the prosodic measures and in section 3.2 we report on the lexical and morphological marking.

\subsection{Prosodic strategies}

\subsubsection{Intonation contour}

As rising intonation is regarded as a marker of politeness, all instances of rising intonation in the data set were noted. A GLMM analysis showed a significant main effect of COST on the production of rising intonation contours $(F(1,201)=8,906$, $p=.003$ ), with rising tunes being used more often in high cost requests than in low cost requests.

\subsubsection{Mean syllable duration}

Statistical analysis showed a main effect of SOCIAL DISTANCE $(F(1,1245)=22,660, p<.001)$ and a main effect of COST $(F(1,1243)=5,691, p=.017)$ on the mean duration of syllables. In other words, the duration of syllables tended to be significantly higher in high social distance situations and also in high-cost situations. This suggests that, independently of their age, children produced significantly longer syllables when they had to request something from someone with higher social distance or when their request implied a higher degree of imposition.

\subsubsection{Average pitch}

There was a significant interaction between AGE and COST in mean pitch $(F(1,1218)=10,951, p<.001)$. In the younger age group, mean pitch values were significantly higher in high cost requests $(p=.006)$. By contrast the effect of COST on pitch was slightly under significance $(\mathrm{p}=.58)$ for the older age group, with higher pitch more frequent in low cost requests.

\subsubsection{Voice quality and intensity}

Statistical analysis showed a main effect of COST on jitter $(F$ $(1,1211)=10,117, p=0.002)$, with significantly less jitter in high cost requests $(\mathrm{p}=0.002)$ compared to low cost requests.

There was a main effect of AGE on shimmer $(F(1,1207)$ $=8,244, p=.004)$, with more shimmer in the older group and a main effect of $\operatorname{COST}(F(1,1207)=7,390, p=.007)$, with more shimmer in high cost requests. However, there was a significant interaction between AGE and $\operatorname{COST}(F(1,1207)=11,977, p<$ $.001)$. In the older group, COST had a significant effect on the production of shimmer $(\mathrm{p}<.001)$, with more shimmer in high cost situations compared to low cost situations, but this difference was not seen in the younger group $(p=.600)$.

There was a significant interaction between AGE and COST in relation to the production of F1-F0, which can be taken as an index of breathiness $(F(1,1218)=8,743, p=.003)$. In the older age group, cost had a significant effect on the production of F1-F0 ( $\mathrm{p}<.001)$, with more breathiness in high cost requests, there was no effect in the younger group $(p=.368)$.

Finally, regarding mean intensity there was a significant interaction between AGE and $\operatorname{COST}(F(1,1243)=8,701, p=$ $.003)$. In the older group, COST had a significant effect on the intensity rate, with higher intensity in low cost requests $(\mathrm{p}=$ $0.003)$. There was no effect of COST in the younger group ( $p=$ $0.224)$.

\subsection{Lexical strategies}

As mentioned above, the only morphosyntactic cue to politeness observable in our data was the use of indirect directives structures, and the only lexical cue sometimes deployed by the children was the mitigator si us plau 'please'. Statistical analyses of the data showed a main effect of COST on children's production of indirect directives $(F,(1,220)=$ $13,260, p<.001)$, with significantly more indirect directives in high cost requests. Furthermore, there was a statistically significant interaction between SOCIAL DISTANCE and AGE on the production of indirect directives $(F(1,220)=12,434, p$ $=.001)$. While in the younger age group there were significantly more indirect directives in low social situations $(p=.007)$, in 
the older age group there were significantly more indirect directives in high social distance situations $(\mathrm{p}=.035)$. This suggests that while children in the younger age group had not yet assimilated the relationship between indirect directives (i.e., using a question to formulate a request) and politeness in Catalan, children in the older group had. Furthermore, there was a main effect of both SOCIAL DISTANCE $(F(1,220)=$ $12,875, p=.001)$ and $\operatorname{COST}(F(1,220)=6,331, p=.013)$ on the presence of si us plau. In other words, the children tended to produce more si us plaus in situations involving higher social distance or higher cost to face.

\section{Discussion and Conclusions}

The main aim of the current study was to investigate (1) whether children know how to deploy mitigation strategies in contexts involving greater social distance and/or higher cost to face, (2) whether children tend to use prosodic strategies more than they use lexical strategies for this purpose and (3) whether their repertoire of mitigation strategies increases with age.

First of all, results of the study showed that preschool children use a wide set of prosodic mitigation strategies, including rising intonation, slower speech rates, less jitter and more breathiness, to render requests appropriately more polite in contexts where either their interlocutor is socially distant from them, or their request implies a high cost of the action to their interlocutor.

More specifically with regard to intonation, the results showed that already by age three children produced significantly more rising intonation contours when producing a request that implied a greater degree of imposition on the hearer. These results are comparable to those reported in [2] for Catalan-speaking adults. However, neither in pre-schoolers nor adults did social distance/power have a significant effect on the choice of intonation contour.

Secondly, focusing on the other prosodic correlates, at age three children manipulated their speech by producing slower speech rates in high social distance and high cost situations, just as adults do. However, there was an interaction between cost and age, so that only the older children produced less intensity, less jitter, more shimmer and more F1-F2 (correlate for breathiness) and near-significantly lower pitch height. Comparing these findings to results found for Catalan-speaking adults [4], it would seem that 5-year-old children can make use of much the same prosodic cues of mitigation as adults (except for shimmer). However, because [4] analysed adult politeness in interactions with only one social parameter, power distance (what we have called social distance), the results of the two studies are not strictly comparable. Nonetheless, they clearly point in similar directions.

Our second finding relates to the use of lexical and morphosyntactic strategies by preschool children to convey politeness relative to their use of prosodic ones. While both age groups used the lexical mitigator si us plau 'please' significantly more in high social distance contexts, only the older children were able to vary their requests morphosyntactically by framing them as indirect directives (questions) rather than direct directives (statements). These results are comparable to previous studies showing that children up to the age of five mainly use direct request strategies ([5], [6], [7], [8], [9], [10], [11]). Furthermore, please as a mitigation strategy appears relatively early in childhood, which could be explained by the heavy emphasis that parents and caregivers place on this lexical item ([12], [13]). Yet other mitigation strategies which can be found in adult Catalan speech, such as the polite form of address vostè vs. the more informal $t u$, the choice of conditional vs. indicative and other lexical hedges (see [4], [23], [24]), are clearly lacking in preschool children's requests.

To sum up, our results provide confirmation that the number of prosodic politeness markers available to young children greatly outweighs their lexical and morphosyntactic repertoire. It seems that prosody in this case helps children to express meanings that they are not able to express yet through lexical and morphosyntactic cues. In other words, prosody does indeed serve a bootstrapping function in the acquisition of pragmatic communication skills. In future work it would be of interest to carry out cross-linguistic comparisons to see whether children acquiring typologically different first languages follow patterns similar to what we have seen here.

\section{Acknowledgements}

We would like to thank Judith Llanes and Anna Massanas, who were the research assistants in this project and helped with data collection. Many thanks also to the staff at the Escola Sant Martí, Escola La Farigola del Clot, Escola Pública Dr. Estalella Graells and Escola Masmitjà preschools for granting us access to and organising the meetings with the preschoolers. Last but not least, we are indebted to Joan Borràs-Comes for invaluable help with the statistics. This research was funded by the Spanish Ministry of Science and Innovation (grant FFI2015-66533-P), and a grant awarded by the Generalitat de Catalunya (2014SGR-925) to the Prosodic Studies Group. The first author also acknowledges an FPI grant from the Spanish Ministry of Science and Innovation (BES-2013-065019)

\section{References}

[1] P. Brown \& S. C. Levinson, Politeness: Some universals in language use. Cambridge UK: Cambridge University Press, 1987.

[2] L. Astruc, M. Vanrell, \& P. Prieto, "Cost of the action and social distance affect the selection of question intonation in Catalan". In M. E. Armstrong, N. Henriksen, \& M. M. Vanrell (Eds.), Interdisciplinary approaches to intonational grammar in IberoRomance (Vol. 93-114). Amsterdam: John Benjamins, 2016.

[3] B. Winter \& S. Grawunder (2012), "The phonetic profile of Korean formal and informal speech registers". Journal of Phonetics, 40(6), 808-815.

[4] I. Hübscher, J. Borràs-Comes, \& P. Prieto, "Prosodic mitigation characterizes Catalan formal speech: The Frequency Code reassessed". Journal of Phonetics, 65, 145-159, 2017

[5] E. B. Greif \& J. B. Gleason, "Hi, thanks, and goodbye: More routine information". Language in Society, 9(2), 159-166, 1980.

[6] K. Aronsson \& M. Thorell, "Family politics in children's play directives". Journal of Pragmatics, 31(1), 25-47, 1999.

[7] G. Axia \& M. R. Baroni, "Linguistic politeness at different age levels". Child Development, 56(4), 918-927, 1985.

[8] J. Bernicot \& S. Legros, "Direct and indirect directives: What do young children understand?" Journal of Experimental Child Psychology, 43(3), 346-358, 1987.

[9] S. Ervin-Tripp \& D. Gordon, "The development of children's requests", In R. Schiefelbusch (Ed.), Communicative Competence: Assessment and intervention (pp. 61-96). San Diego: College Hill Press, 1986. 
[10] M. Georgalidou, "The contextual parameters of linguistic choice: Greek children's preferences for the formation of directive speech acts", Journal of Pragmatics, 40(1), 72-94, 2008.

[11] K. Nakamura, "The use of polite language by Japanese children's narratives", Japanese/Korean Linguistics, 3, 84-99, 1999.

[12] K. Nakamura, "The acquisition of linguistic politeness in Japanese", In M. N. R. Mazuka, \& Y. Shirai (eds.), The handbook of East Asian psycholinguistics: volume II Japanese (pp. 110115). Cambridge: Cambridge University Press, 2006.

[13] C. Ryckebusch \& H. Marcos, "Speech acts, social context and parent-toddler play between the ages of 1;5 and 2;3", Journal of Pragmatics, 36(5), 883-897, 2004.

[14] E. Bates, Language and context: the acquisition of pragmatics. New York: Academic Press, 1976.

[15] M. A. Nippold, L. B. Leonard, \& A. Anastopoulos, "Development in the use and understanding of polite forms in children", Journal of speech and hearing research, 25(2), 193202, 1982.

[16] Hübscher, I., Wagner, L., \& Prieto, P., "Young children's sensitivity to polite stance expressed through audiovisual prosody in requests", Proceedings of Speech Prosody, Boston, 897-901, 2016.

[17] K. Hirsh-Pasek, M. Tucker, \& R. M. Golinkoff, „Dynamic systems theory: Reinterpreting "prosodic bootstrapping" and its role in language acquisition. Signal to syntax Bootstrapping from speech to grammar in early acquisition, 449-466 ST - Dynamic systems theory: Reinterpreti, 1996.

[18] A. Christophe, M. Nespor, M. T. Guasti, \& B. Van Ooyen, "Prosodic structure and syntactic acquisition: The case of the head-direction parameter", Developmental Science, 6(2), 211220, 2003.

[19] I. Hübscher, N. Esteve-Gibert, A. Igualada, \& P. Prieto, "Intonation and gesture as bootstrapping devices in speaker uncertainty", First Language, 37(1), 24-41, 2017.

[20] L. Bosch \& N. Sebastián-Gallés, "Evidence of Early Language Discrimination Abilities in Infants from Bilingual Environments", Infancy, 2(1), 29-49, 2001.

[21] M. M. Vanrell, I. Feldhausen \& L. Astruc, "The Discourse Completion Task in Romance prosody research: status quo and outlook", In I. Feldhausen, U. Reich, \& M. M. Vanrell (eds.) Methods in prosody: A view from Romance languages. Berlin: Language Science Press (in press).

[22] E. Uçar \& Ö. A. Bal, "Preschoolers' use of requests", Dilbilim Araştırmaları Dergisi, 2, 25-43, 2015.

[23] P. Boersma \& D. Weenik, "Praat: doing phonetics by computer [Computer program]. Version 6.0.30. Retrieved 22 July 2017 from http://www.praat.org/.

[24] M. Fivero, "A Speech Act Analysis of Polite Verb Forms in Romance", Proceedings of 6th Linguistic Symposium on Romance Languages, Ottawa, Canada, 1976.

[25] L. Payrató \& J. M. Cots, The pragmatics of Catalan. Berlin/ Boston: Walter de Gruyter Gmbh, 2011.

[26] P. Prieto, „Intonational phonology of Catalan“, In S.-A. Jun (ed.), Prosodic typology II: The phonology of intonation and phrasing (pp. 43-80). Oxford: Oxford University Press, 2014. 